\title{
Gonzalo Wilhelmi, Romper el consenso: la izquierda radical en la transición española (1975-1982), Madrid, Siglo XXI, 2016, 430 pp.
}

Romper el consenso, de Gonzalo Wilhelmi, es un importante trabajo que se suma a otros publicados recientemente y realiza una contribución destacada en el sentido de poner en cuestión la tesis de una transición "pacífica" hacia un orden institucional democrático en la España inmediatamente posterior a la muerte de Francisco Franco. Wilhelmi analiza la acción de los partidos que pretendieron ofrecer una alternativa de izquierda, primero al franquismo y luego al régimen de acuerdos de la transición. Mediante fuentes orales y abundante documentación interna y pública de las organizaciones, recupera las voces y miradas del activismo de izquierda que aportó a organizar las grandes huelgas contra el franquismo, el naciente movimiento de la mujer o el movimiento estudiantil, enfrentando la represión de la dictadura en su etapa final y de los gobiernos de la transición. El libro contiene un apéndice documental con los nombres y causas de la muerte de 253 víctimas del terrorismo estatal y paraestatal durante los gobiernos anteriores a 1982. A su vez, aporta documentación y testimonios orales sobre todas las formas de violencia represiva estatal y paraestatal del periodo: desde las torturas en las comisarias y centros de detención o el gatillo fácil, hasta la represión estatal directa de las fuerzas de seguridad, pasando por la acción de grupos parapoliciales de características fascistas.

A partir de esta sólida base documental, el libro da cuenta del ascenso obrero y de la izquierda en la fase final del franquismo y busca también explicar la crisis terminal de esa izquierda, cuyas organizaciones más influyentes decidieron la medida extrema de disolverse a principios de la década del 80. Siguiendo el rol de estas corrientes, el libro recupera las características del ascenso de movilización popular de la última etapa de la dictadura reseñando la historia del movimiento obrero combativo, el movimiento de mujeres, el movimiento ambiental, la movilización de los presos comunes, el movimiento por la paz y contra el ingreso de España a la OTAN, y el movimiento ciudadano.

La investigación permite aportar al conocimiento de las posiciones de las distintas organizaciones políticas y de su práctica militante, así como de su inserción en las luchas del periodo. Las organizaciones mayoritarias de la izquierda (el Partido del Trabajo de España y la Organización Revolucionaria de los Trabajadores) provenían del maoísmo. Las centrales obreras impulsadas por el PTE y la ORT obtuvieron, en las primeras elecciones sindicales realizadas en 1978, 5.583 y 3.164 delegados respectivamente, contra 66.066 de Comisiones Obreras. La Liga Comunista Revolucionaria, el único partido trotskista, es descripto 
por el autor como un partido volcado a las movilizaciones sociales pero sin un proyecto político que lo colocara en condiciones de proyectarse como alternativa.

En la primera parte del libro, Wilhelmi señala que un elemento fundamental de la caracterización realizada por estas organizaciones era la idea de que la dictadura sería incapaz de avanzar en un proceso de reforma. En general, primaba ampliamente la idea de que tendria lugar inevitablemente una ruptura democrática que llevaría a la formación de un gobierno provisional. En la perspectiva del PTE y la ORT, este gobierno llevaría adelante la amnistía para los presos, el desarme del aparato represivo, y representaria un paso adelante en la lucha por el socialismo. La consigna del gobierno provisional era una consigna de colaboración con todas las fuerzas democráticas, o sea, una consigna etapista.

De acuerdo con el análisis realizado por el autor, la iniciativa del sector reformador del régimen, secundada por el PCE y el PSOE, de avanzar en una democracia regimentada-incluida la amnistía para los criminales del franquismo, la represión contra las organizaciones populares, la pervivencia de la monarquía, la consagración constitucional de la "unidad indivisible de España" bloqueando los reclamos nacionalestomó a la izquierda por sorpresa. Las mayores formaciones de izquierda (PTE y ORT) votaron en favor de la Constitución de 1978, luego de una campaña de denuncias en contra de la misma por los aspectos reaccionarios anteriormente reseñados. Pesó más, en su consideración, la idea de la democracia como etapa necesaria en un eventual camino al socialismo que las denuncias concretas sobre la propia constitución y sus acuerdos fundacionales.

El libro reconstruye de qué manera esta evolución llevó a la crisis a ambas organizaciones, lo que derivó en su disolución, un hecho notable tratándose de partidos que llegaron a tener la capacidad de convocar huelgas generales locales y hacer elegir miles de delegados sindicales en nombre de centrales propias. ¿Por qué no se dio una ruptura con el orden vigente? El autor rechaza la tesis de que el PCE fue el factor determinante para encuadrar al movimiento obrero y evitar la caída de la dictadura. Sostiene, en cambio, que la clase obrera no advirtió una relación entre sus mejoras inmediatas y la caída del régimen por medio de un gobierno provisional. Una tesis discutible dado que la subjetividad del movimiento obrero combativo de la etapa se forjó, justamente, luchando por la caída de la dictadura.

Otro debate destacado en la obra es la cuestión de la democracia interna al interior de la izquierda, que el autor caracteriza como prácticamente nula, excepto en la LCR. Los comités locales, por ejemplo, eran electos por la dirección y no por la base, y no existía libertad de 
tendencias. Contra la posición que entiende que la falta de democracia interna fue producto de la situación de clandestinidad y represión, el autor la explica por la "cultura política" de las organizaciones. Efectivamente, el PTE y la ORT provenían del stalinismo, lo cual no puede desconocer que actuaron, incluso luego de la legalización, bajo un marco represivo que resulta un bloqueo objetivo a la democracia interna de cualquier partido.

Otro punto destacado del análisis es el del marco de acción sindical de la izquierda. Las corrientes mayoritarias de la misma actuaron por fuera de los grandes sindicatos. Se retiraron prematuramente de Comisiones Obreras (CC.OO.) y no intentaron disputar su dirección al PCE. $\mathrm{El}$ autor apoya esta postura en su balance de la acción de la LCR, que sí permaneció en CC.OO. Para el autor, la expulsión de la dirección de Navarra de CC.OO. demuestra que esta línea era una vía muerta, porque el PCE no iba a tolerar oposiciones de peso en el sindicato. No se puede desconocer, sin embargo, que el encuadramiento burocrático de CC.OO. se produjo como resultado no de la simple voluntad o no del PCE de tolerar oposiciones, sino de un reflujo de la movilización independiente en la medida en que se iba afirmando una tendencia de colaboración política de los sindicatos con el Estado que fue parte fundamental de la transición. La expresión más importante de esta tendencia fue la firma por parte del PCE y el PSOE de las cláusulas económicas de los pactos de la Moncloa, que implicaron una reducción salarial y el aumento de la desocupación.

Un último punto que se destaca en la obra es la relación de la izquierda con los movimientos nacionalistas del País Vasco, Catalunya, Galicia y Canarias. En general, la izquierda apoyó los reclamos autonómicos. Pero la combinación entre la crisis de la izquierda y la fuerza de un nacionalismo que conservó una agenda activa de reclamos contra la democracia emergente determinó que los movimientos nacionalistas ocuparan totalmente el espacio ganado por la izquierda en estas zonas. Esto vale especialmente para el País Vasco y el progreso de Herri Batasuna en una de las zonas donde el movimiento obrero combativo tenía mayor impulso.

En conjunto, Romper el consenso representa una obra de interés histórico y político que realiza un análisis riguroso sobre el desarrollo de la izquierda española en el periodo de la transición y es, al mismo tiempo, una historia de la propia transición, vista desde la izquierda.

Juan Garcia (Universidad de Buenos Aires)

$$
* * *
$$

